American Journal of Environmental Sciences 4 (3): 185-188, 2008

ISSN 1553-345X

(C) 2008 Science Publications

\title{
Sustainable Management of Effluents from Small Piggery Farms in Mexico
}

\author{
J.L. de Victorica-Almeida, M. Galván-García and R. Ayala-Ruiz \\ Instituto de Ingeniería, Universidad Nacional Autónoma de México, \\ Cd. Universitaria, 04510 DF, México
}

\begin{abstract}
In Mexico, pig farming is the third most important livestock activity due to its contribution to the total meat production. However, it is estimated that around $38 \%$ of pig farms dispose their wastewaters without any treatment directly into the nation's water bodies, which in turn has a severe impact in the environment. One reason for not treating is the high costs involved, especially for small pig farms. Therefore, a study was performed to develop a low cost and easy to operate treatment system suitable for this type of wastewater and with a quality that allows the reuse of the final effluent within the farm. The pilot study was performed in packed reactors to evaluate the influence of the hydraulic superficial charge on the removal of BOD and COD from a partially treated effluent produced in a small swine farm. BOD and COD initial concentrations ranged from $1,173-2,318 \mathrm{mg} \mathrm{L}^{-1}$ and $2,146-4,119 \mathrm{mg} \mathrm{L}^{-1}$, respectively. The reactors were three PVC columns, $10.16 \mathrm{~cm}$ in diameter and $1.32 \mathrm{M}$ in height, each with $6.4 \mathrm{~L}$ of total volume and packed with a fixed bed of volcanic rock (tezontle), $47.7 \%$ porosity and $7 \mathrm{~mm}$ mean diameter. The columns were operated in sequence with download flow under Superficial Hydraulic Charges (SHC) of 1,3 and $5 \mathrm{~m}^{3} / \mathrm{m}^{2} \mathrm{~h}$, with recirculation. The results show treatment efficiencies of 97.3-98.9\% for BOD and $84.8-92.6 \%$ for COD, with recirculation time between 16 and 27 days. The results of this study are being used to establish the basic elements for designing and implementing suitable wastewater treatment systems to recycle and reuse these effluents in small scale piggery farms in Mexico, to promote sustainable management and reduce water pollution.
\end{abstract}

Key words: Treatment, pig wastes, fixed bed packed reactors, effluent recycling, reuse

\section{INTRODUCTION}

In Mexico, pig farming is the third most important livestock activity, after bovine and poultry. During 2005 , the total production of pork meat was $1,100,000$ tons, of which only a $3.5 \%$ were exported and the internal per capita consumption was $15.3 \mathrm{~kg}^{[1]}$. Although pig production is a highly profitable activity its contribution to the gross national product is only around $0.3 \%$, while it has a very important negative impact on the environment, especially in the water. Pig farms require large amounts of water for their production process. The resulting wastewaters contain high concentrations of organic matter, dissolved and suspended solids, turbidity, colour and pathogenic microorganisms and should be disposed so as to not jeopardize human or domestic animal's health and without polluting final disposal sites such as soils, rivers, lakes and reservoirs.

At present, around $38 \%$ of pig farms (mainly small pig farms) dispose their solid and liquid wastes without any treatment directly into water bodies and soils. This is due to a limited economy and/or availability of space to construct and operate conventional treatment systems developed for such purposes, like aerobic, anaerobic and facultative oxidation ponds, constructed wetlands, etc.
For these reasons, this research project was proposed with the aim of fulfilling this deficiency, by way of the development of a treatment system with characteristics that permit waste treatment to a level that allows the recycling of water within the farm facilities, thus saving important amounts of reclaimed water, promoting sustainable management and reducing water and soil pollution.

\section{MATERIALS AND METHODS}

Wastewaters used in the experiments were collected from the effluent of a settling tank in a pig farm located at the municipality of Otumba, state of Mexico. The farm produces basically sucking pigs and is designed for a population of 120 females. Water uses in the farm yield between 37 and $40 \mathrm{~m}^{3}$ of wastewater per week, whose characteristics and mean composition are shown in Table 1.

Equipment: As shown in Fig. 1, a system of three sequential fixed bed download flow reactors (columns) with recirculation were used; the reactors were $10.16 \mathrm{~cm}$ diameter and $1.32 \mathrm{M}$ high, with a total volume of $32.1 \mathrm{~L}$. The three columns were packed with $80 \mathrm{~cm}$ of $7 \mathrm{~mm}$ mean diameter volcanic rock (tezontle), with an apparent volume of $6.4 \mathrm{~L}$ and $47.7 \%$ porosity.

Corresponding Author: J. L. de Victorica-Almeida, Instituto de Ingeniería, Universidad Nacional Autónoma de México, Cd. Universitaria, 04510 DF, México Tel: +525556233600/8655 


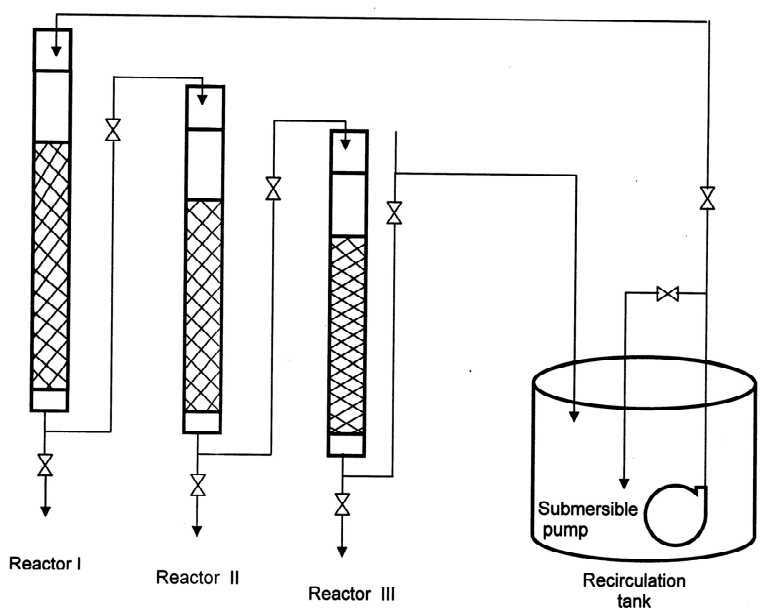

Fig. 1: Schematic diagram of the download flow fixed bed reactors used

Table 1: Characteristics and composition of wastewater used in the experiments

\begin{tabular}{lllc}
\hline Parameter & Mean value & Range & No. of samples \\
\hline pH & 8.3 & $8.08-8.44$ & 3 \\
Turbidity (NUT) & $1,909.66$ & $712-2,946$ & 3 \\
Color (Pt-Co) & $5,127.33$ & $3,120-7,392$ & 3 \\
TCOD $\left(\mathrm{m} \mathrm{L} \mathrm{L}^{-1}\right)$ & $2,997.33$ & $2,146-4,119$ & 3 \\
BOD5 $\left(\mathrm{mg} \mathrm{L}^{-1}\right)$ & $1,694.66$ & $1,173-2,318$ & 3 \\
BOD5/TCOD & 0.564 & $0.546-0.584$ & 3 \\
TS $\left(\mathrm{m} \mathrm{L} \mathrm{L} \mathrm{L}^{-1}\right)$ & 3,400 & $2,925-3,965$ & 3 \\
TVS $\left(\mathrm{mg} \mathrm{L}^{-1}\right)$ & 1,510 & $1,215-1,885$ & 3 \\
TFS $\left(\mathrm{m} \mathrm{L} \mathrm{L}^{-1}\right)$ & 1,890 & $1,710-2,080$ & 3 \\
TSS $\left(\mathrm{m} \mathrm{L} \mathrm{L}^{-1}\right)$ & 975.2 & $245-2,125$ & 3 \\
VSS $\left(\mathrm{mg} \mathrm{L}^{-1}\right)$ & 629.66 & $155-1,367$ & 3 \\
FSS $\left(\mathrm{mg} \mathrm{L}^{-1}\right)$ & 345.63 & $90-758$ & 3 \\
VDS $\left(\mathrm{mg} \mathrm{L}^{-1}\right)$ & 880.43 & $518-1,063.30$ & 3 \\
\hline
\end{tabular}

The ratio between free and apparent volume was 0.59 . Recirculation was performed with a submersible 1/3 HP pump installed in a $150 \mathrm{~L}$ polypropilene tank.

Experimental procedure: Prior to the experimental trials, the reactors were packed with sieved tezontle obtained from the filter operating with settled wastewater from the pig farm. Then, the reactors were flooded with the settled water and remained this way for 7 days, to allow the biomass formation on the packing material. Afterwards, the reactors were operated with download flow, under superficial hydraulic charge of $4 \mathrm{~m}^{3} \mathrm{~m}^{-2} \mathrm{~h}^{-1}$, with continuous recirculation, during 10 days, on which time Biochemical Oxygen Demand (BOD) reached the cuasi-stationary conditions in the effluent (Fig. 2). At this point, it was considered that the biomass was stabilized and the experimental trials were initiated, feeding over the top of the first reactor the settled wastewater, using subsequent Superficial Hydraulic Charges (SHC) of 1,3 and $5 \mathrm{~m}^{3} \mathrm{~m}^{-2} \mathrm{~h}^{-1}$, which correspond to Hydraulic Retention Times (HRT) of 0.1 ,

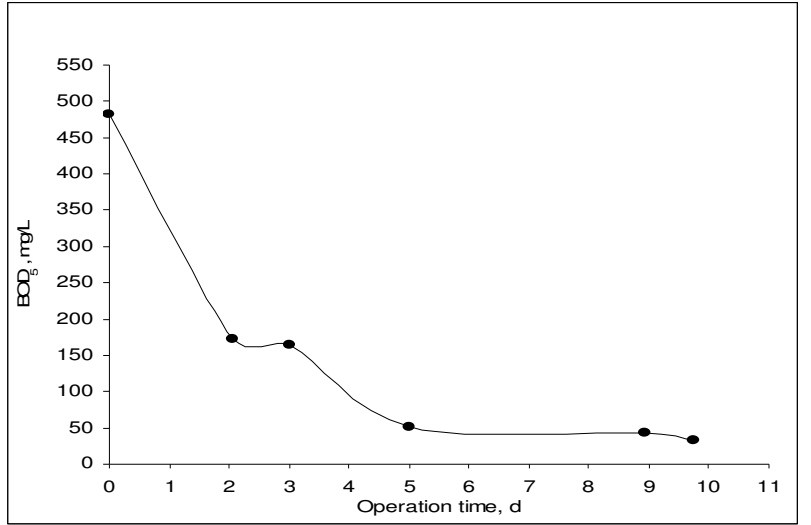

Fig. 2: Behaviour of BOD in the effluent during the stabilization period $\left(\mathrm{SHC}=4 \mathrm{~m}^{3} \mathrm{~m}^{-2} \mathrm{~h}^{-1}\right)$

0.03 and 0.02 days and Superficial Organic Loads (SOL) of $28.15,38.23$ and $55.63 \mathrm{~kg} \mathrm{BOD} \mathrm{m}^{-2}$ days $^{-1}$, respectively.

The operation time of each trial was determined until the cuasi-stationary conditions were observed in the concentrations of BOD and total COD (TCOD) in the effluent of the system. In every trial at the starting of the operation, the next parameters were determined in the influent: $\mathrm{Ph}$, turbidity, colour, TCOD, non filtered $\mathrm{BOD}_{5}$, Total Solids (TS), Total Volatile Solids (TVS), Total Fixed Solids (TFS), Total Suspended Solids (TSS), Volatile Suspended Solids (VSS) and Fixed Suspended Solids (FSS). During the performance of each trial, all the above mentioned parameters were determined only in the effluent of the system. However, temperature (T) was determined always in both, the influent and the effluent. All analysis were made according to the Standard Methods ${ }^{[2]}$ and when needed, using a HACH-DR/2010 equipment.

\section{RESULTS AND DISCUSSION}

As it is shown in Fig. 1, of the mean content of TS $\left(3,400 \mathrm{mg} \mathrm{L}^{-1}\right)$ present in the wastewater, only $44.4 \%$ (TVS $=1,510 \mathrm{mg} \mathrm{L}^{-1}$ ) was susceptible to biochemical degradation, requiring for this a $\mathrm{BOD}_{5}$ of $1,694.66 \mathrm{mg} \mathrm{L}^{-1}$, equivalent to $56.5 \%$ of the TCOD $\left(\right.$ TCOD $\left.=2,997.33 \mathrm{mg} \mathrm{L}^{-1}\right)$. It can be seen also that $58.3 \%$ of TVS were constituted of dissolved organic material $\left(\mathrm{VDS}=880.34 \mathrm{mg} \mathrm{L}^{-1}\right)$ and the rest $(\mathrm{VSS}=$ 629.66) by suspended organic material.

On the other hand, in Fig. 3 are shown the results of the effect of the Superficial Hydraulic Charges (SHC) on the BOD declining. It can be seen that, even under different BOD concentrations in the feeding water, this parameter follows a reduction pattern similar for all cases. However, the required time for reaching stationery conditions increases, as it was expected, as the SHC are increased. It is important to say that during the time of the experimentation there was no clogging 
Am. J. Environ. Sci., 4 (3): 185-188, 2008

Table 2: Characteristics of the effluent obtained under different experimental conditions

\begin{tabular}{|c|c|c|c|c|c|c|c|c|c|}
\hline \multirow[b]{3}{*}{ Parameter } & \multicolumn{9}{|c|}{ Superficial Hydraulic Charge $\mathrm{m}^{3} \mathrm{~m}^{-2} \mathrm{~h}^{-1}$} \\
\hline & \multicolumn{3}{|l|}{1} & \multicolumn{3}{|l|}{3} & \multicolumn{3}{|l|}{5} \\
\hline & Initial & Final & $\eta(\%)$ & Initial & Final & $\eta(\%)$ & Initial & Final & $\eta(\%)$ \\
\hline$\overline{\mathrm{pH}}$ & 8.44 & 8.79 & - & 8.08 & 8.77 & - & 8.40 & 8.99 & - \\
\hline Turbidity (NTU) & 712 & 108 & 84.83 & 2071 & 67 & 96.76 & 2946 & 57 & 98.06 \\
\hline Colour (Pt-Co) & 3120 & 836 & 73.20 & 4870 & 764 & 84.31 & 7392 & 630 & 91.47 \\
\hline TCOD (mg/L) & 2146 & 326 & 84.80 & 2727 & 343 & 87.42 & 4119 & 302 & 92.66 \\
\hline $\mathrm{BOD}_{5}(\mathrm{mg} / \mathrm{L})$ & 1173 & 28 & 97.61 & 1593 & 43 & 97.30 & 2318 & 25 & 98.92 \\
\hline $\mathrm{BOD}_{5} / \mathrm{TCOD}$ & 0.546 & 0.085 & - & 0.584 & 0.125 & - & 0.562 & 0.082 & - \\
\hline $\mathrm{TS}(\mathrm{mg} / \mathrm{L})$ & 2925 & 1568 & 46.39 & 3310 & 1936 & 41.51 & 3965 & 1957.69 & 50.62 \\
\hline TVS (mg/L) & 1215 & 448 & 63.12 & 1430 & 516 & 63.91 & 1885 & 746.92 & 60.37 \\
\hline TFS (mg/L) & 1710 & 1120 & 34.50 & 1880 & 1420 & 24.46 & 2080 & 1480.76 & 28.80 \\
\hline TSS (mg/L) & 245 & 14.19 & 94.20 & 555.6 & 13.57 & 97.55 & 2125 & 9 & 99.57 \\
\hline VSS (mg/L) & 155 & 13.54 & 91.26 & 367 & 12.85 & 96.49 & 1367 & 7 & 99.48 \\
\hline FSS (mg/L) & 90 & 0.64 & 99.28 & 188.9 & 0.71 & 99.62 & 758 & 2 & 99.73 \\
\hline TDS (mg/L) & 2680 & 1553.81 & 42.02 & 2754.40 & 1922.43 & 30.20 & 1840 & 1948.69 & -5.90 \\
\hline VDS (mg/L) & 1060 & 434.46 & 59.01 & 1063.30 & 503.15 & 52.68 & 518 & 469.92 & 9.28 \\
\hline FDS $(\mathrm{mg} / \mathrm{L})$ & 1620 & 1119.36 & 30.90 & 1691.10 & 1419.29 & 16.07 & 1322 & 1478.76 & -11.8 \\
\hline $\mathrm{T}_{\text {operation }}(\mathrm{d})$ & 16 & & & 20 & & & 27 & & \\
\hline
\end{tabular}

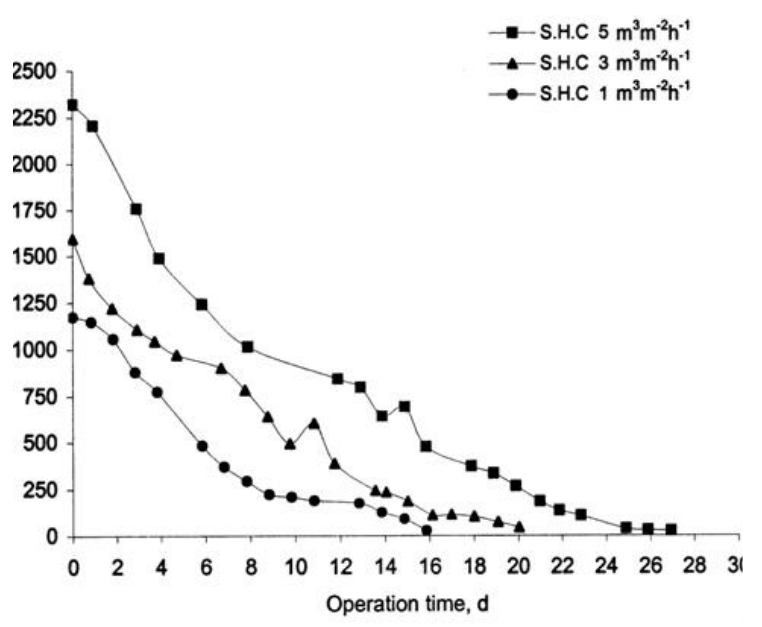

Fig. 3: Behaviour of the BOD with respect to the hydraulic superficial charges used

in the reactors, although eventually some biofilm detachments occurred, giving way to the discontinuity (pikes) observed in the upper and middle curves of Fig. 4. Probably this was due to the increments in SHC and, therefore, the increased flow velocity inside the reactors.

In Table 2, it is shown the effect of the SHC on the removal of TCOD. It can be seen that the curves follow a declining pattern similar to that of BOD, under similar operation conditions. Also it can be seen that as the SHC increases, the operation time required to attain the cuasi-stationary conditions also increases. In this case, as in the BOD, the discontinuities in the declining curves are due to the detachment of the biofilm; this happened mainly when the reactors were operated at SHC of 3 and $5 \mathrm{~m}^{3} \mathrm{~m}^{-2} \mathrm{~h}^{-1}$.

In Table , the characteristics of the effluent at the end of the trials are shown. It can be observed that under any of the SHC it is possible to reduce more than 97\% the content of organic matter in the wastewater (BOD); also it can be seen reductions of $84-92 \%$ of the

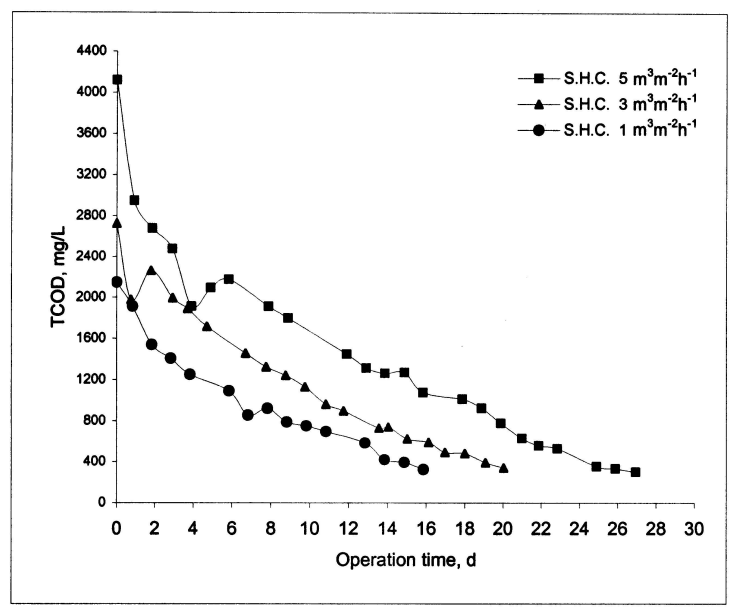

Fig. 4: Influence of the SHC on the removal of TCOD

TCOD, $84-98 \%$ of turbidity and $73-91 \%$ of colour. With respect to the content of volatile solids, it is known that biological processes are, in general, efficient for their removal. In this case, the removal efficiencies varied from 91 to $99 \%$.

In the same table it can be observed, also, that the processes evaluated is sufficient to remove more than 99\% of Fixed Suspended Solids (FSS); however, this reduction seems not to be due to the assimilation of 
these type of solids by the microorganisms (biomass), but rather to the extracellular enzymatic processes that transform them in soluble compounds; therefore, their concentration decreases in the effluent, giving very low values of FSS. This situation is reflected in the increase of the total dissolved and fixed dissolved solids (TDS, FDS) in the effluent, giving way (as can be seen in the table) to negative efficiencies for these parameters, under the SHC of $5 \mathrm{~m}^{3} \mathrm{~m}^{-2} \mathrm{~h}^{-1}$. This situation can be due, also, to a process of concentration of the solids by means of water evaporation during the 27 days of this particular trial.

\section{CONCLUSIONS}

The results show that the fixed bed download flow reactors, with recirculation, as the ones used in this study, are a viable option to efficiently reduce ( $\eta>97 \%)$ suspended and dissolved organic material present in settled wastewater from piggery farms.

This type of treatment system has the capacity to buffer the variations of the superficial organic load in the influent (28.15-55.63 $\mathrm{kg} \mathrm{BOD} \mathrm{m}^{-2}$ days $^{-1}$ ), without decreasing the treatment efficiency.

The effluent obtained had sufficient quality to permit its reuse within the farm, such as in cleaning the pigs and their pigsties, washing the yards, etc.; this also allows to free the corresponding volumes of first use water, to favour the sustainable management and to reduce the resulting pollution of soils and receiving water bodies due to their disposal in them.
With this study, it can be established the basic elements for the design and implementation of treatment systems in other farms with similar characteristics.

\section{ACKNOWLEDGMENTS}

This research study was funded by the Universidad Nacional Autónoma de México, by means of Project PAPIIT No. IN223003. The authors thank Mr. Cruz Bautista Muñoz, owner of the Farm, for the facilities provided.

\section{REFERENCES}

1. SAGARPA, 2007. Sistema de Información y Estadística Agroalimentaria y Pesquera (SIAP). http://www.sagarpa.gob.mx/Dgg/prod0001.htm

2. APHA, AWWA, WEF, 1995. Standard Methods for the Examination of Water and Wastewater. 19th Edn. Washington, DC. 